\title{
Using Education to Enhance Gender Equality in the Workplaces in China
}

\author{
Shuzheng Zhou ${ }^{1}$, Ruohao Chen ${ }^{2}$ \\ ${ }^{1}$ Huazhong University of Science and Technology, Wuhan, China \\ ${ }^{2}$ Columbia University, New York, USA \\ Email: zhoushuzheng190716@outlook.com
}

How to cite this paper: Zhou, S.Z. and Chen, R.H. (2019) Using Education to Enhance Gender Equality in the Workplaces in China. Open Journal of Social Sciences, 7, 259-272.

https://doi.org/10.4236/jss.2019.79020

Received: August 19, 2019

Accepted: September 24, 2019

Published: September 27, 2019

Copyright (c) 2019 by author(s) and Scientific Research Publishing Inc. This work is licensed under the Creative Commons Attribution International License (CC BY 4.0).

http://creativecommons.org/licenses/by/4.0/

\begin{abstract}
As the economy develops and people's aspirations grow in China, Chinese women are more aware of gender inequality in the workplaces. Though the working conditions have been greatly improved, Chinese women are still discriminated and underestimated in the labor market and many of them have to give up their rights and opportunities when they are facing the dilemma of work and personal life. To enhance gender equity in the workplaces, this article discusses the factors leading to the unequal situation and focuses on the means of education to improve young people's awareness of gender equality and their ability to deal with gender inequality in the workplaces. During the research, we designed a workshop on gender equality education and delivered it to fellow college students. In this article, the teaching plan of the workshop will be explained in detail and the students' feedback is recorded.
\end{abstract}

\section{Keywords}

Gender Equality, Female, Workplace, Means of Education

\section{Introduction}

According to European Institute for Gender Equality [1], gender equality is achieved when women and men enjoy the same rights and opportunities across all sectors of society, including economic participation and decision-making, and when the different behaviors, aspirations and needs of women and men are equally valued and favored. According to the Global Gender Gap Report 2018 [2], China ranked the $103^{\text {rd }}$ out of the 149 investigated countries for gender equality, which suggests that gender inequality is a common phenomenon in different domains in China and great efforts and various measures are required to improve the circumstances for women. However, gender equality and femin- 
ism have not gained enough attention in the public space in China, even after the MeToo Movement caused a short but dramatic swirl on the media. In this article, based on global gender gap reports conducted by references [3] [4] [5] and literature review of gender equality, we focus on gender inequality in the workplaces in China, discussing factors leading to the phenomenon and exploring educational measures to enhance college students' awareness of gender equality and their ability to deal with gender inequality in the workplace by the means of education. We also discuss a workshop we designed and delivered to college students under the principles of three adult learning theories including Critical Thinking, Transformative Learning and Experimental Learning, and draw findings and insight from the implementation of the workshop and the feedback of the participants.

\section{The Situation of Gender Equality in the Workplace in China}

The gender inequality in workforce participation and economic leadership remains unsatisfying, though the economic achievements in the past decade in China are significant. Female workers suffer inequality and discrimination in promotion opportunity, wage, work time, and leadership. According to the Global Gender Gap Report 2018 [2], 68.8\% of women participated in China's labor force, compared to $82.8 \%$ of men, which is one of Asia-Pacific's highest labor force participation rates for women. Despite this, this rate does not mean that Chinese women have equal positions as men in the labor market. In contrast, compared with men, Chinese women have fewer opportunities in employment and earn lower wage, but suffer more underestimation and prejudice in promotion. According to a poll in China Daily [6], Chinese women on average earn 22 percent less than their male coworkers. Meanwhile, females are supposed to sacrifice more to balance work and family life. The following phenomena are typical in Chinese workplaces as signals of gender inequality.

Firstly, it cannot be denied that not all positions in China are open to women and men equally. Human Rights Watch released its report [7], saying that gender stereotypes and discriminatory language are prevalent in job advertisements in China. Nineteen percent of postings for civil service jobs in 2018 listed a requirement or preference for male candidates. Besides, gender inequality is even more serious on the Internet and the high-tech industries. According to a report by Zhilian Hiring [8] that talked about the recruitment of females in China, $43 \%$ of the female postgraduates believed they have been discriminated by gender as a job hunter, and the figure for the female with a master's degree of engineering was $80 \%$. Female's ability is very likely to be underestimated in many high-income industries, such as IT and finance, which leads to the severe gender imbalance in related companies, including Huawei, where female's proportion was about $20 \%$ from 2013 to 2017 steadily (Figure 1) [9], and Alibaba, where only $1 / 3$ of the employers were women [10]. 
Secondly, the gap of wage (Table 1) and work time (Table 2) between women and men is also a crucial aspect of gender inequality. With no legislation mandating equal pay, China has a wide wage gap between the two genders. The [2] shows Chinese women earned on average 36 percent less than men for doing similar work, although women worked 44 mins per day more on average. And almost 45 percent of Chinese female employers' work is unpaid, in comparison with 18.9 percent of males'. Additionally, female employers are required to retire 5 to 10 years earlier than male, which furtherly depresses the income of women, as well as limits their promotion.

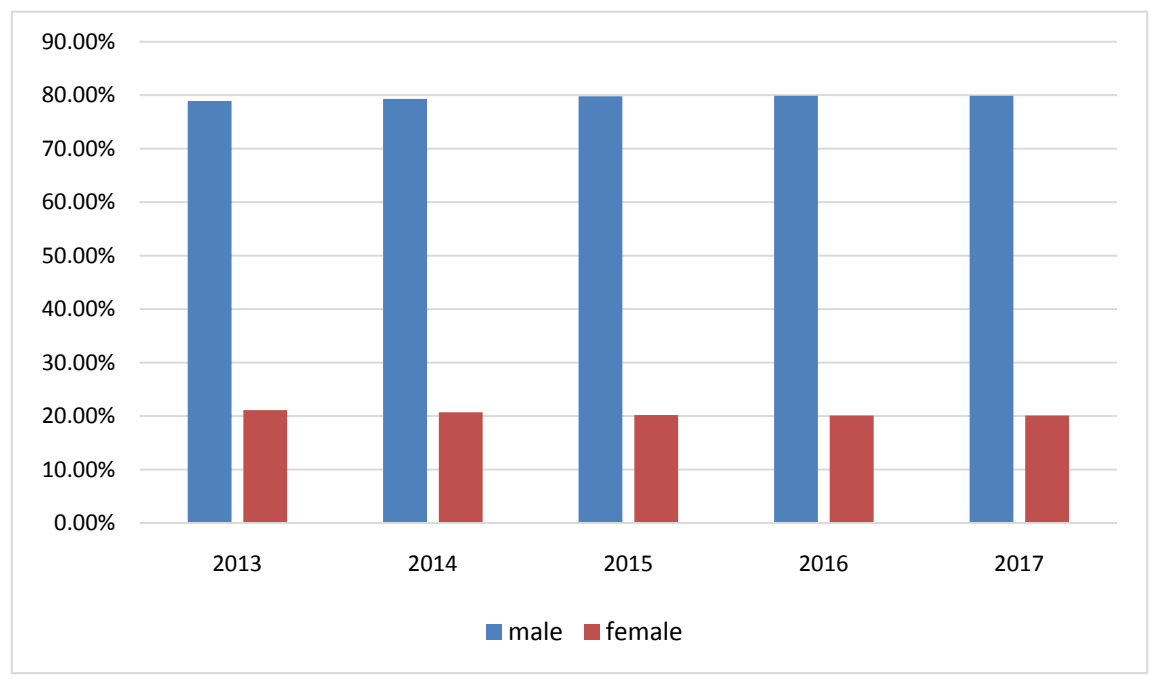

Figure 1. Gender ration of Huawei employees in recent years (resources from [9]).

Table 1. The global gender report 2018 (source from [2]).

\begin{tabular}{ccccccc}
\hline & rank & score & avg & female & male & $\mathrm{f} / \mathrm{m}$ \\
\hline EPP $^{\mathrm{a}}$ & 86 & 0.653 & 0.586 & - & - & - \\
$\mathrm{LP}^{\mathrm{b}}$ & 64 & 0.831 & 0.669 & 68.8 & 82.8 & 0.83 \\
WESW $^{\mathrm{c}}$ & 74 & 0.643 & 0.645 & - & - & 0.64 \\
$\mathrm{EEI}^{\mathrm{d}}$ & 73 & 0.621 & 0.510 & 12,789 & 20,586 & 0.62 \\
LSOM $^{\mathrm{e}}$ & 122 & 0.201 & 0.329 & 16.8 & 83.2 & 0.20 \\
PTW $^{\mathrm{f}}$ & 1 & 1.000 & 0.753 & 51.7 & 48.3 & 1.07 \\
\hline
\end{tabular}

${ }^{a}$ Economic participation and opportunity; ${ }^{b}$ Labor force participation; ${ }^{c}$ Wage equality for similar work (survey); ${ }^{\mathrm{d}}$ Estimated earned income (PPP, US\$); ${ }^{\mathrm{e}}$ Legislators, senior officials and managers; ${ }^{\mathrm{f}}$ Professional and technical workers.

Table 2. Comparison of working hours between married female and male.

\begin{tabular}{cccc}
\hline & Married female & Married male & Gap (male higher than female ) \\
\hline $\begin{array}{c}\text { Time for working } \\
\text { (hours per week) }\end{array}$ & 46.1 & 50.4 & $9 \%$ \\
$\begin{array}{c}\text { Time for family } \\
\text { (hours every day) }\end{array}$ & 2.6 & 2.0 & $-22 \%$ \\
\hline
\end{tabular}


Thirdly, pregnant women are judged unfairly in workplace, especially in promotion and job-hunting. Some female employees would even be required not to bear a child during the contract period in the interview, and more than $11.5 \%$ of the women say their promotions were held against by pregnancy [8]. In addition, it has been proved by [8], that in China, married women pay $22 \%$ more time in family and $9 \%$ less time in work than men. Many women are forced to focus more on family and child caring at the cost of their careers and promotions.

Those statistics and examples suggest clearly that men hold more power and gain more benefit than women in Chinese labor market.

\section{The Factors Leading to the Gender Inequality in China}

There are complex factors contributing to gender inequality in China, including cultural, political, socioeconomic, historical and other factors. Some factors have a traditional origin while others have emerged in recent years. From our perspective, four main factors account for the serious situation of gender inequality in China today.

Firstly, the cultural and historical influence is one of the main reasons leading to the discrimination and stereotypes against female, both in family and society. Dominated by the patriarchy for thousands of years, Chinese people have taken the differentiated treatment by gender for granted. In Confucianism, the backbone of traditional Chinese culture, females were in an inferior status. Confucius once said, "Of all people, only women and servants are the most difficult to get along with. If you are familiar with them, they will lose the manner, if you alienate them, they will complain", and he refused to accept female students. Inheriting and developing Confucius's thoughts, many other ideologists promote the ideas about gender discrimination including, gentlemen should keep away from kitchen and women should do all the housework, having no male heir is the gravest offence against filial piety, and all women should obey their husbands' orders completely based on "three principles and four virtue". Influenced by Confucianism, those ideas like men to be stronger than women both mentally and physically, men should be respectable and women humble, and it is a virtual if a woman doesn't receive education were widely spread and implemented strictly in ancient China. Although the ridiculous rules have been abolished, the negative influence is still not eliminated completely. Many people still believe that men ought to get preferential treatments in the workplace, because they are more intelligent and work harder than women, which makes it tough for people to abandon the gender prejudice and treat women equally in workplaces.

Being oppressed and manipulated by those patriarchal thoughts for centuries, Chinese women do not have strong consciousness of rebellion, and many feminist ideas were not well accepted by Chinese government and influential figures, and worldwide feminist movements are not well accepted in China. For instance, the "MeToo" movement's hashtag on China's popular microblogging website, 
Weibo, was removed by censors shortly after it gained traction online, and famous figures including movie stars and athletes hardly express their opinions publicly about it [11]. It is hard to deny that the Chinese feminism is too weak to beat the traditional prejudice and cultural stereotype, and Chinese female workers are not strong and determined enough to fight against the discrimination and underestimation in the workplaces.

Additionally, compared with the inveteracy of gender prejudices, Chinese people lack awareness in general problems, because social and cultural mobility in China has not improved coordinatingly with the fast-developing economy. Nowadays, gender issues are not well discussed in public in China. Focused on economic interests, many Chinese care more about money than their equal rights and responsibilities in daily social life, which makes it harder to achieve gender equality.

Secondly, the existing law and regulations are deficient to protect and promote females' human rights. Owing to legal flaws, many violent or ill-willed behaviors against women would not be punished by law, and many measures which could promote gender equality cannot be implemented. For example, the marital rape has not been considered as crime by law, and the equal maternity leave between genders is almost impossible to be signed in Chinese law now, although it has been put into force in Sweden and some other countries.

Besides, some scholars and critics have pointed out that gender equality does not have the same status or the same effects as other basic state policies, such as the one-child policy [12]. Concentrating on the factors related to economy, the law-enactor in China does not supervise the implementation of laws protecting female rights as strictly as those connected to national interests and economic development. For instance, many companies fire female employees who make no mistakes but become pregnant, while most of them do not need to pay any price of breaking the labor law, because of the lack of investigation and tiny chance to win in a court. And those companies even do not need to face ethical and public criticism because people's low equal consciousness.

Thirdly, China's economic reforms have resulted in a variety of setbacks for women, including the diminishment of employment opportunities for women, the widened gender wage gap, the lack of childcare options and the resurgence of traditional stereotypes about women's work [13]. With the upgrading of industrial structure and the development of market economy, the gap of wages and social positions among different industries are being widened. People work in senior industries like High-technology, information technology and finance industries have higher income and superior status in both society and family, where men have more opportunities than women because of the stereotypes and different educational chances.

Moreover, it cannot be denied that market economy is intensifying the business competition. To improve employees' competitiveness, many companies favor men more than women in the interview. In the traditional patriarchal ideol- 
ogy, men are more rational and stronger physically and mentally, which makes them better workers and leaders. Besides, employers could even avoid paying for the maternity leaves by hiring men only.

Meanwhile, many women today are under heavier pressure in both work place and personal life, resulting from the big gap of wealth and heavy life pressure, because they are provided with fewer opportunities and a lower wage. According to the [8], women pay 15 percent more time in the family on average than men, but only 9 percent less in workplace. Moreover, many women are asked to sacrifice their own careers and give up chances of promotion to squeeze even more time for housework and childcare, because of the rigid gender role, which limits their professional development and also worsens the gender inequality in different aspects.

Fourthly, the education system is one of the most significant reasons of gender inequality in modern China. The exam-oriented education in China emphasizes the ability of memorizing and practicing but neglects the training for students' critical thinking and creativity. As a result, it is a common problem that Chinese people ignore the observation and analysis of social issues, including gender inequality. Without the ability of critical thinking and questioning, Chinese citizens are easily manipulated by the traditional patriarchal ideology and gender prejudices and are unwilling to fight back.

In addition, though it has been widely confirmed that sex education is necessary for kids and teenagers, which helps them keep healthy and build correct gender conception, sex education in China is severely lacking in basic education. Girls are not systematically taught how to protect themselves from gender discrimination and sexual assault, and boys are not taught how to respect women and protect them from gender inequality.

\section{Designing a Workshop to Promote Gender Equality for College Students}

To promote the gender consciousness among college students, we designed a workshop, consisting of two lessons, for a small class of about 10 students. The workshop was also an attempt to figure out what content was needed to make the education for gender equality a success and how the content could be delivered effectively. We chose college students because they are mature enough to talk about gender equality and may have to face gender issues in the workplaces in the near future.

As we all known, university life is a crucial stage in people's social exploration and self-perception. The knowledge we learn and the perspective we accept might change our life including our marriages and careers. Besides, universities are the cradles of talents, where leaders and progressivists grow up. Gender equality education could change the society by influencing those people and then encouraging them to spread and practice the thoughts. Overall, a workshop focused on gender equality is necessary in the college. 


\subsection{Goals}

To promote gender equality in China, this workshop focuses on how college students deal with gender inequality in their daily life and work. Based on critical thinking [14], this workshop provides learners opportunities to hunt and examine their assumptions of gender equality, which would enrich their perspectives about genders. Given definition, statistics and examples, learners would be able to improve their awareness about gender equality and attain a solid understanding of the general situation of gender equality in China. Transformative learning [15] would be adopted in this workshop, by offering learners a safe place to talk about their own experience and help them heal as well as find a way to fight against gender inequality. The objectives are to enhance the situation of Chinese gender equality among students, and some of them could devote to spreading the knowledge of GE to others.

\subsection{Content}

1) The definition of gender equality

2) The phenomenon of different treatments to women and men

3) The situation of gender inequality in China, and teacher and students' own experience of gender inequality

4) The measures to deal with the prejudice and discrimination about gender in their daily life and work

\subsection{Academic Framework}

The workshop is planned for a small scale (less than 10 students in a class) to guarantee the effectiveness of discussions. The teaching methods and activities designed in this curriculum are based on Critical Thinking, Transformative Learning, and Experiential Learning.

Critical thinking is a model of thinking about any subject, content or problem in which the thinker improves the quality of his or her thinking by skillfully analyzing, assessing, reasoning, and reconstructing it [16]. Not correlated with IQ, personality, major or measures of intelligence, critical thinking is self-directed, self-disciplined, self-monitored, and self-corrective thinking. The process of critical thinking includes hunting assumptions, checking assumptions, seeing things from different viewpoints and taking informed action [14]. Integrating the practice of critical thinking with gender equality knowledge, this $f$ not only provides the students with new perspectives of gender equality, but also gives them the ability to question the old ideology and stereotypes.

Transformative learning refers to the process by which we transform our taken-for-granted frames of reference (meaning perspectives, habits of mind, mind-sets) to make them more inclusive, discriminating, open, emotionally capable of change, and reflective so that they may generate beliefs and opinions that will prove more true or justified to guide action [15]. [15] believes that transformative learning usually results from a "disorienting dilemma" which is 
triggered by a life crisis or major life transition, although it may also result from an accumulation of transformations in meaning schemes over a period of time. Less dramatic predicaments, such as those created by a teacher, also promote transformation.

Experiential learning is the process of learning through experience, and is more specifically defined as "learning through reflection on doing" [17]. Experiential learning entails a hands-on approach to learning that moves away from just the teacher at the front of the room transferring their knowledge to students. It makes learning an experience that moves beyond the classroom and strives to bring a more involved way of learning [18]. One of the most famous systems of experiential learning is Kolb's experiential learning cycle [17], which is a circulating system with four steps, including concrete experience, reflective observation, abstract conceptualization and active experimentation.

\subsection{Teaching Plan}

\section{Lesson 1}

To introduce the conception of gender equality, the teacher starts the class by a discussion with students, giving them chances to express their opinions freely about the unequal treatments by gender in reality, according to their available gender knowledge. The discussion would last about 30 minutes.

Based on students' ability of critical thinking, their assumptions will include difference perspectives drawn from both physiological structure and social stereotypes. Every assumption will be listed on the blackboard and teacher will lead them to check these assumptions one by one and find out whether they are supported by solid evidence. And the debate among students would be encouraged. After examining the assumptions, students are supposed to be able to judge the accuracy and reliability of those assumptions by themselves and build the connection between the improper assumptions and the phenomenon of gender inequality in modern society. So, in the 20-minute discussion, the conceptions and theories of gender equality would become more vivid and pellucid to students.

The second part of this class is giving a 25-minute lecture about gender equality to learners. After directing student to hunt and check their assumptions, we could give them a short lecture to define gender equality academically and introduce the current situation of gender equality in China through statistics and realities. The comparisons between China and other countries will also be given, along with some successful examples about advancing the situation of gender equality through effective policies and social activities. The lecture is important in broadening students' insight and giving them new perspectives. From the lecture, they would notice that gender inequality exists in all aspects of our life, including survival and health, education attainment and so on. And they might realize that they have been manipulated by the patriarchal ideology for a long time and ignore many discrimination and stereotypes unconsciously. At the end of the class, there would be five minutes left to gather students' opinions about 
what impresses them most and what they want to learn in

Lesson 2.

The assignment after Lesson 1 is reading Chinese Female in Workplace Report from 2015 to 2018, summarizing the changes and giving a comment.

\section{Lesson 2}

The points of Lesson 2 include helping students have a deeper understanding about gender equality and find a way to protect themselves and fight against gender discrimination.

The first part of the class is giving feedback to students. Students could discuss what we should do and how we can do to improve the situation of gender equality in China. Occupying 10 minutes, the discussion is based on the reports and examples given in Lesson 1.

Aiming to promote students' awareness and behaviors, this workshop adopts various classroom activities to combine the conceptions and data with students' own experience. Based on the theories of transformative and experiential learning as well as critical thinking, the classroom activities will facilitate learners' change and help them get a profound awareness and thoughts about gender equality.

Transformative learning theory states that the process of "perspective transformation" has three dimensions: psychological (changes in understanding of the self), convictional (revision of belief systems), and behavioral (changes in lifestyle) [19]. As it was mentioned, transformative learning could contribute to the change of mindset, but some well-designed and more profound classroom activities are necessary if the teacher wants to promote students' transformation in belief system and lifestyle.

Role-play game would be an ideal activity in the second part of this class (30 min). By encouraging students to play roles of the other gender in specific scenarios like job interviews, political elections and family argument, this activity would put learners into the role's position, which might provide them with new insights and perspectives. Male would be able to understand gender inequality more deeply and be aware that they need to protect women from gender prejudice, when they react in female's situation and speak from females' perspectives. And females could prepare themselves better and notice the importance of fighting back, when they have an intuitive sense of what they need to face in the future. For example, through a job interview scenario, the man who plays the female interviewee would be shocked, facing the unequal treatments including questioning for his ability and energy based on gender discrimination, unfair payment, and limitation for pregnancy, which he might never need to deal with as a male. Noticing the serious gender inequality situation in economic participation and opportunities, he might respect female co-workers more and make some changes when he becomes an HR or even a powerful policy-maker. Meanwhile, the woman who plays the male interviewer could look into the causes of women discrimination in workplace, and then they could prepare 
themselves to protect their legitimate rights and interests. Besides, both females and males could learn from others' reaction in the role-playing, which might give them new ideas about how to deal with gender inequality in daily life.

The emphasis of the role-play is asking students to think and behave from different genders' standpoint, react in the face of the other's dilemma, and then reflect on the experience and learn from each other. From this activity, they may know the importance of breaking gender stereotypes and discriminations. As a result, they may recognize how to fight against these stereotypes and discriminations.

The third part of lesson 2 is experience sharing, which would last about 20 minutes. In this part, it is essential for teacher to provide a safe place to learners, where they could talk about their own stories about gender discrimination or even sexual assault freely. Teacher need to do the best to listen patiently and react nicely. Retelling and analyzing their experience in a proper way, teacher might be able to build resonance between tellers and listeners, healing the teller and resorting to listeners' respect and care, as well as showing the importance of achieving gender equality to the listeners. However, if no one wants to share, the teacher could give students a case. Students could discuss what they would do if they are the central figures of the case. Based on the theory of transformative learning, this part is designed to stimulate students to transform their references of meaning or habit of minds by sharing their own perspectives and exploring alternative perspectives with others. It would be an ideal learning occasion if learners are shocked by others' ways of thinking and viewing the same issue because it may bring learners more "Aha moments".

The final part of this workshop is writing a letter to stress the importance of promoting gender equality, offering a proposal and sharing the thoughts. The recipient could be the UN, the government, a student council, or any person in the world. At the end of the workshop, students are expected to give some feedbacks about the class, in which they could reflect on what they have learned in this workshop, what have affected them most deeply, how the workshop has changed their minds, and how we can improve this workshop.

\section{Result and Discussions}

After practicing the teaching plan for 2 times with 7 students in total (4 girls and 3 boys), the authors testified the effectiveness and usefulness of the workshop by gathering their feedbacks. All of them admitted that this workshop was useful in broadening their knowledge and improving their awareness of gender equality. Most of them were shocked by the statistics which showed the serious condition of gender equality in the workplaces in China. For example, Student A (female, 19 years old) said, "It has never occurred to me that we still have so much gender discrimination in the labor market today. Those numbers shocked me. I didn't even realize the influence of the economic reforms on gender equality before." Student B (female, 21 years old) said, "We Chinese women are used to accepting 
all the prejudices and underestimations without even questioning and fighting back. Lots of people in China, including me, would sometimes take gender prejudices for granted. We never ask why women should retire earlier than men, or why some positions are only available for male." Student C (male, 22 years old) said, although he had already noticed the severe gender discrimination against women in the workplaces in his HR internship, he never tried to find the causes or make changes. The GE workshop transformed his perception of gender equality and encouraged him to think more deeply about protecting females' right and shouldering his social responsibility. As we can see from the participants' feedback, young people's awareness of gender equality is far from enough due to a lack of exposure to discussion and useful information in China. Through the workshop of gender equality, young people not only have more access to key information but also gain experience to conceptualize gender equality and come up with possible strategies to deal with gender inequality.

The two lessons have given students first-hand experience of discussing gender equality in the workplaces. Students experienced or tackled common gender discrimination through scenarios, role plays and case studies, which gave them holistic experience and impact. This workshop also prompted them to think about what they need to do to protect themselves and what they can do in the future to break gender stereotypes and change the unequal condition. Student D (male, 23 years old) expressed in the class, it is hard for him to stand from a female's point before when gender discrimination occurred, let alone to fight for women. However, he said, "we could not just accept gender discrimination in silence if we want a more equal and just world", after the role-play game, in which he played a female employee, facing all the unreasonable and even humiliated requirements about marriage and pregnancy by himself. "I will respect my mother, my girlfriend and other women around me more, and if I see gender discrimination in the workplaces, I will speak out for them", Student D said. In addition, Student A mentioned, our fight could barely make a big change to China today, and the cost is high, so learning to protect ourselves is more practical. We could make compromises now, but we should make differences in the future, when we become parents, employers, teachers, policymakers or executers. According to transformative learning theory [15], adults may change their points of view or habits of mind when they are stuck in a "dis-orienting dilemma". The workshop put the participants in a difficult role play, namely a "dis-orienting dilemma", which helped some students change their perspective of gender issues and get a deeper understanding of gender equality. With renewed perspectives, some students felt motivated to take informed action.

However, the students also mentioned, in the role-play game, it is almost impossible for them to truly think from the stance of the opposite gender, so their reactions could barely be used as references. For instance, in the interview scenario, when being asked not to bear a child in 5 years, Student E (male, 22 years old), who played a female job hunter said directly, "It's none of your business. 
And I do not need the job offered by someone who insulted me in the face." But in real life, most females may not choose this way to fight back, especially when the chance is valuable. So, it is essential for the teachers to draw students' attention to their identity in the role play and guarantee the authenticity of the scenarios.

From the participants' feedback, we found the role play relies on students' level of knowledge, moral conscience and empathy. It is extremely hard for some students to understand the victims of gender inequality, let alone behave in their shoes. To ensure the viability of the activity, we would add a case study in lesson 2 before the role play. With a better understanding of the context, students may play the role of the other gender in the scene more successfully, which will give them a more realistic experience to reflect on.

In short, the workshop is useful in helping students construct the idea of gender equality and encourage them to confront the stereotypes and discriminations. However, more means of education remain to be explored and more attempts should be made to attract the public's attention to gender equality education. If the workshop could be popularized, the ideas of gender equality would be widely discussed and studied in the public space, which would enhance the possibility of making gender equality an accepted reality by all sectors of the society.

\section{Conclusions}

This article focuses on the situation of gender equality in the workplace in China and explores possible educational means to improve young people's awareness of gender equality, as well as their ability to deal with gender inequality in the workplace in China.

With the application of adult learning theories and the use of information from academic and official sources, the workshop we delivered served as an effective and impactful way to enhance students' awareness of gender equality and their ability to deal with gender inequality. In our workshop, students were given a safe space to talk about gender issues and gain the first-hand experience by taking part in the activities we organized, which helped them change their ways of thinking or modify their perspectives of genders. From our experience, we are convinced that authentic experience in education will touch student's soul and change their behaviors. If gender equality education is popularized among students, gender equality may be a reality in the future. We also believe that other educational theories and tools will be useful and effective if more educators and scholars invest their time and effort in developing relevant curriculum.

However, there are certain limitations in our research project. We focused on gender inequality in the workplace only, but the problem exists in different domains in China and each domain has its own characteristics. More discussion and explorations in education are needed to draw appropriate solutions to this issue. We conducted the workshop for only one time and students' feedback was 
collected on the spot. In other words, we are not able to follow up and examine if the workshop has a long-term impact on the students. To testify the effectiveness of gender equality education, more attempts should be made, and facilitators should find ways to evaluate the long-term effect of education. Last but not least, the collective voice for gender equality in China is still weak and schools and teachers in general are not very interest in this topic, so we not only need high-quality educational programs for gender equality, we also need to gain support from the government, the public, and schools and teachers of different levels.

Using education to enhance gender equality in the workplaces in China is a long-term process, which cannot be achieved only by a single curriculum in the university. However, if we persist in spreading the thoughts of GE among families, schoolmates, colleagues, and gain support from the government, the public, and schools and teachers of different levels, gender equality will gradually become a reality. This workshop is an immature attempt, but we believe gender equality education will become a common practice at schools in the near future.

\section{Conflicts of Interest}

The authors declare no conflicts of interest regarding the publication of this paper.

\section{References}

[1] European Institute for Gender Equality (2010) Concepts and Definition of Gender Equality. https://eige.europa.eu/gender-mainstreaming/concepts-and-definitions

[2] World Economic Forum (2019) Global Gender Gap Report 2018. Geneva, 63-64.

[3] World Economic Forum (2016) Global Gender Gap Report 2015. Geneva.

[4] World Economic Forum (2017) Global Gender Gap Report 2016. Geneva.

[5] World Economic Forum (2018) Global Gender Gap Report 2017. Geneva.

[6] China Daily (2018) Gender Gap Pay Narrows in China. http://www.chinadaily.com.cn/a/201803/07/WS5a9f6971a3106e7dcc140271.html

[7] Human Rights Watch (2018) Only Men Need Apply: Gender Discrimination in Job Advertisements in China.

[8] Zhilian Hiring (2018) The Situation of Chinese Female in Workplaces Report 2017.

[9] Huawei (2018) Huawei Sustainable Development Report 2017.

[10] Matt Sheehan (2015) Jack Ma Says Women Executives Are Alibaba's "Special Sauce”. The Huffington Post (21 May 2015).

[11] Cheng, J. (2018) \#MeToo in China? Censors Try to Stifle Talk of Sextual Harassment in China. World Magazine. Snapshots of China (18 Jan. 2018).

[12] Zhao, Y. (2017) (Un)doing Gender Equality in China. In: Ortenblad, A., Marling, R. and Vasiljevic, S., Eds., Gender Equality in a Global Perspective, Routledge, New York, 24. https://doi.org/10.4324/9781315639505-4

[13] Dasgupta, S., Matsumoto, M. and Xia, C. (2015) Women in the Labour Market in China. ILO, Bangkok.

[14] Brookfield, S.D. (2011) Teaching for Critical Thinking: Tools and Techniques to 
Help Students Question Their Assumptions. John Wiley \& Sons, Hoboken.

[15] Mezirow, J. (2000) Learning to Think Like an Adult. In: Meziro, J., et al., Eds., Learning as Transformation: Critical Perspectives on a Theory in Progress, Jossey-Bass, San Francisco, 3-33.

[16] Scriven, M. and Paul, R. (1987) Defining Critical Thinking. 8th Annual International Conference on Critical Thinking and Education Reform. http://www.criticalthinking.org/pages/defining-critical-thinking/766

[17] Kolb, A.Y. and Kolb, D.A. (2009) Experiential Learning Theory: A Dynamic, Holistic Approach to Management Learning, Education and Development. In: Armstrong, S.J. and Fukami, C.V., Eds., The SAGE Handbook of Management Learning, Education and Development, SAGE Publications Ltd., Thousand Oaks, 42-68. https://doi.org/10.4135/9780857021038.n3

[18] Wikipedia (2018). https://en.wikipedia.org/wiki/Experiential_learning

[19] Clark, M.C. and Wilson, A.L. (1991) Context and Rationality in Mezirow's Theory of Transformational Learning. Adult Education Quarterly, 41, 75-91.

https://doi.org/10.1177/0001848191041002002 